\title{
Clinical Reasoning: A case of bilateral orbital mass lesions presenting with acute monocular vision loss
}

Nirav Bhatt, MD, Avi Landman, MD, Charif Sidani, MD, and Negar Asdaghi, MD

Neurology ${ }^{\circledR}$ 2018;91:e2192-e2196. doi:10.1212/WNL.0000000000006624
Correspondence

Dr. Bhatt

drnrbhatt@gmail.com

\section{Section 1}

An 80-year-old man with medical history of hypertension developed a sudden loss of vision in the left eye without any associated pain, flashes, or floaters. The review of systems was negative for any headaches, jaw claudication, scalp or temporal tenderness, or other symptoms suggestive of polymyalgia rheumatica (PMR). The patient's medications were benazepril and amlodipine for the treatment of hypertension. Clinical examination showed normal vital signs. Visual acuity testing revealed 20/20 vision on the right and hand movement perception only in the temporal field of the left eye, with no light perception on the nasal field of the same eye. Pupils were $3 \mathrm{~mm}$ bilaterally, round, and reactive with a relative afferent pupillary defect on the left. Dilated funduscopic examination was unremarkable on the right side and revealed macular whitening and retinal blanching with cherry-red spot on the left. Temporal artery pulses were present. The remainder of the neurologic examination was unremarkable. Laboratory investigations including erythrocyte sedimentation rate, C-reactive protein, lipid profile, and glycosylated hemoglobin were normal.

\section{Question for consideration:}

1. What is your differential diagnosis?

GO TO SECTION 2

From the Departments of Neurology (N.B., A.L., N.A.) and Radiology (C.S.), Leonard M. Miller School of Medicine, University of Miami, FL.

Go to Neurology.org/N for full disclosures. Funding information and disclosures deemed relevant by the authors, if any, are provided at the end of the article. 


\section{Section 2}

A careful ophthalmologic history is an essential initial step in the evaluation of vision loss. Monocular vision loss localizes to an intrinsic ocular pathology (cornea, anterior chamber, or lens) or retinal or prechiasmatic lesions. Patients with primarily mechanical retinal lesions such as retinal detachment typically complain of photopsia before the vision loss whereas vascular lesions of the optic nerve or retina present with sudden, painless, altitudinal, or complete vision loss. Acute lateralized monocular vision loss with relative sparing of the temporal field was suggestive of an intraorbital lesion compressing the optic nerve. An MRI of the orbits with and without contrast was performed, which revealed bilateral enhancing intraconal mass lesions (figure, A), left greater than right. However, the funduscopic findings in this case were consistent with acute central retinal artery occlusion (CRAO). Therefore, the following differential diagnosis was considered in this patient:

1) CRAO is caused by occlusion of the central retinal artery, most commonly from an embolic source. Common etiologies include atherosclerotic plaques along the course of the carotid arteries, aorta, or a cardioembolic phenomenon. CRAO usually presents with an acute monocular vision loss involving the entire visual field. Infrequently, CRAO can be secondary to an inflammatory arteritis, giant cell arteritis (GCA) being the most commonly diagnosed underlying condition. The patient underwent a CT angiogram of the head and neck, which was unremarkable, and a cardiac workup including a 2D echocardiogram and 48hour cardiac monitoring did not reveal a potential cardioembolic source of ischemia. As mentioned earlier, ESR and CRP were normal, and the patient did not have any systemic symptoms suggestive of GCA.

2) Compressive optic neuropathy from a space-occupying lesion in the orbit usually presents with gradual vision loss and multiple cranial neuropathies along with exophthalmos.
Orbital cavernous venous malformations (cavernous hemangioma) are the most common vascular lesion of the orbit in adults, accounting for $5 \%-7 \%$ of all orbital mass lesions. Although they are largely asymptomatic, sometimes they present with painless, progressive proptosis rather than acute isolated loss of vision.

Orbital pseudotumor is a nonmalignant idiopathic inflammation of the orbital tissues and the most common cause of painful orbital mass in adults. Patients commonly present with pain, proptosis, ptosis, periorbital edema, and restriction of ocular motility. It seldom presents with isolated acute vision loss, especially in the absence of the features mentioned above. Based on its location, it includes conditions such as dacryoadenitis and autoimmune myositis. Tolosa-Hunt syndrome is the term used to indicate its involvement of the cavernous sinus.

Cavernous-carotid fistula is an abnormal communication between the internal carotid artery and the cavernous sinus and can be traumatic or spontaneous. It presents with chemosis, proptosis, pulsatile exophthalmos, and other cranial nerve deficits. It can lead to ophthalmic vein varices that over time may also lead to central retinal vein occlusion.

3) Although ischemic optic neuropathy (ION) commonly presents with altitudinal visual deficit, it is worth considering in a patient with acute vision loss and vascular risk factors. Nonarteritic ION is the most common form of ION. It is analogous to small vessel disease stroke of the optic nerve and has a similar risk factor profile including hypertension, diabetes mellitus, hypotension, and rarely use of vasopressor medications. The clinical features are swollen optic disc, decreased cup-to-disc ratio (normally 0.3), and uncommonly, simultaneous involvement of the fellow eye.

Arteritic ION usually occurs in patients over 70 years of age. GCA is the most common etiology. It is usually accompanied by local and systemic features suggestive of an underlying inflammatory condition such as new-onset headache, jaw pain, fever, myalgias and weight loss. Simultaneous involvement of the fellow eye is uncommon. 
A

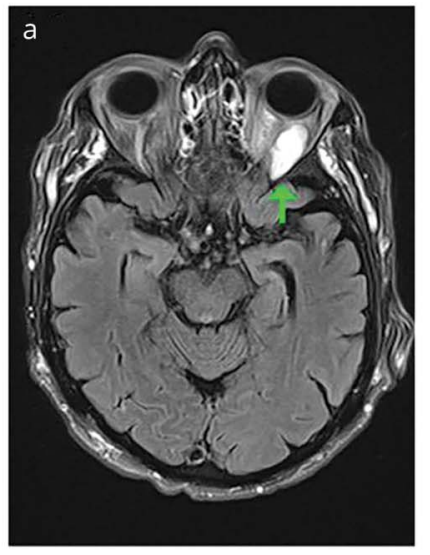

$\mathrm{B}$

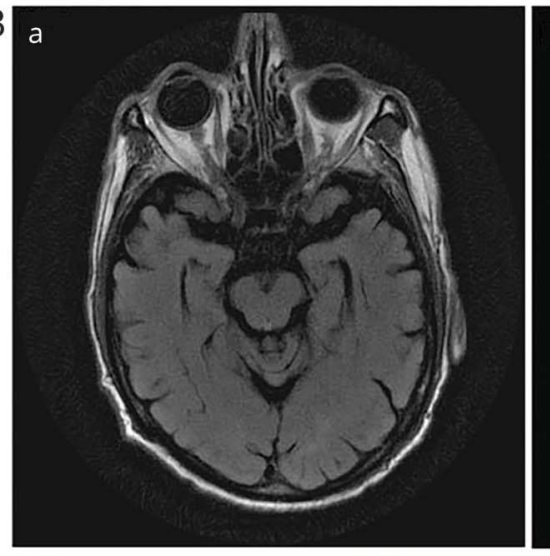

C a

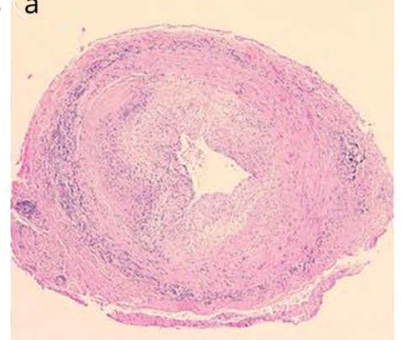

b
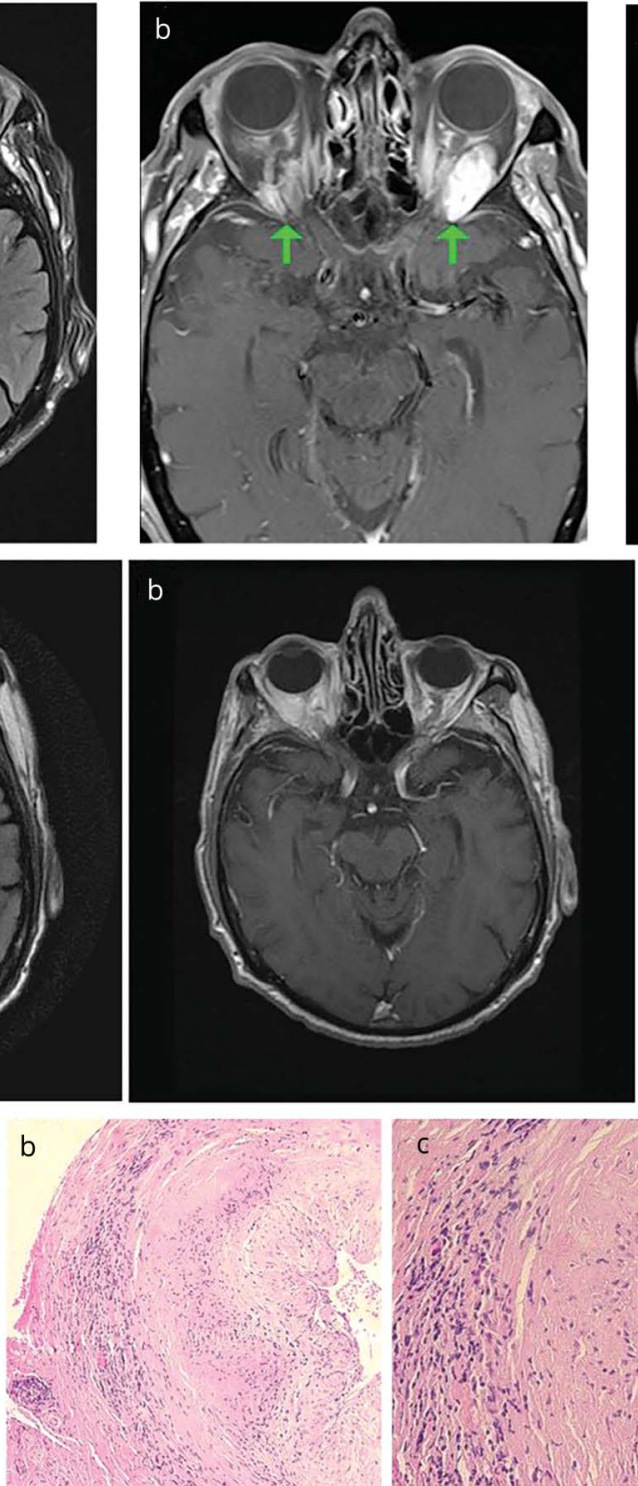

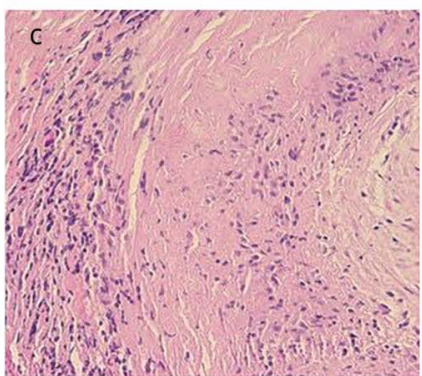

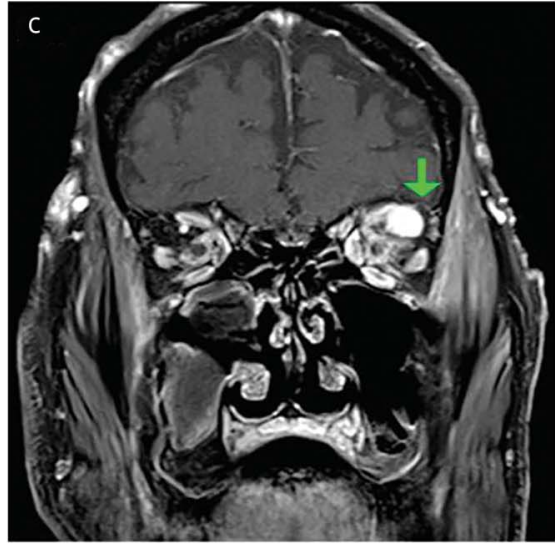

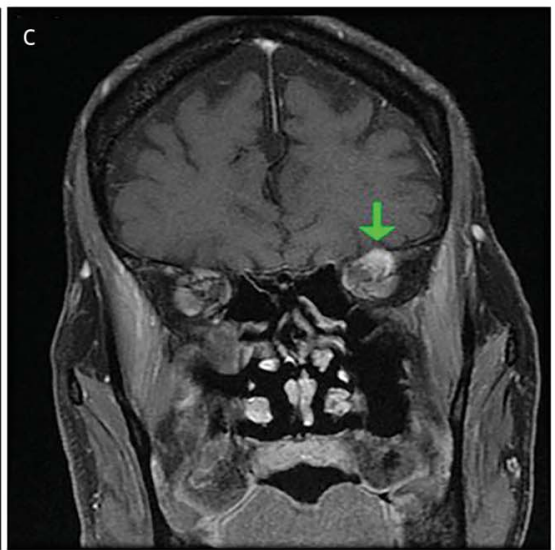

d - EVG stain

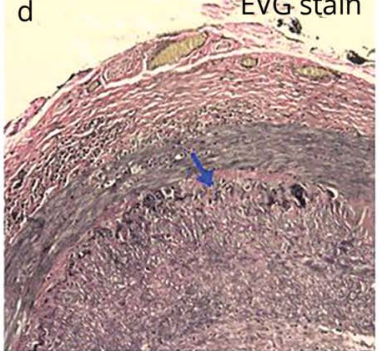

(A) (A.a: axial FLAIR; A.b: axial T1 + contrast; A.c: coronal T1 + contrast). MRI brain shows bilateral orbital enhancement, left greater than right (green arrows). (B) (B.a: axial FLAIR; B.b: axial T1 + contrast; B.c: coronal T1 + contrast). MRI brain shows resolution of bilateral orbital enhancement (green arrow). (C) (C.a, C.b, C.c $\times 4, \times 10, \times 40)$ : panarteritis. (C.d [×10]): elastic Van Gieson stain shows fragmentation of the internal elastic lamina (blue arrow). 


\section{Section 3}

\section{Questions for consideration:}

1. What are the next steps in the management of this patient?

2. What additional tests would you order to narrow the differential diagnosis?

A complete workup for an embolic source remained negative. Keeping the possibility of an uncommon presentation of a common and treatable condition in mind, the diagnosis of GCA was considered in this elderly man with vision loss, despite the lack of usual systemic and inflammatory markers associated with GCA. Given the time sensitivity of GCA treatment, empiric therapy with steroids was initiated $(1,000 \mathrm{mg} / \mathrm{d}$ for 3 days, followed by $60 \mathrm{mg}$ orally daily with a tapering schedule afterwards). A cerebral angiogram did not reveal any arterial or venous pathology. The patient's symptoms improved marginally, with perception of hand movements in both temporal and nasal field of the left eye. A repeat MRI of the brain and orbit was performed 3 days after the treatment that showed a significant reduction in the size of the orbital mass (figure, B). Eventually a temporal artery biopsy (TAB) showed transmural inflammation with histiocytes and lymphocytes along with moderate amount of intimal hyperplasia and fragmentation of the internal elastic lamina, thus confirming the diagnosis of GCA (figure, C)

\section{Discussion}

Monocular loss of vision is an ocular emergency. Urgent assessment, rapid diagnosis, and early treatment initiation has been shown to improve clinical outcomes and reduce disability. We present a case of GCA presenting as lateralized monocular vision loss in a context of bilateral intraorbital mass lesions that responded to steroids.

While the differential diagnosis of the intraorbital masses includes intraorbital lymphoma, sarcoidosis, and meningioma, we propose that these lesions were perhaps a manifestation of a local inflammatory response along the GCA spectrum, as has been previously reported in literature. ${ }^{1-3}$ Furthermore, the lack of a ring-enhancing appearance of these masses argues against a lymphoma. Similarly, response to steroids and the imaging features, both on MRI and head CT, do not support the likelihood of a meningioma. Sarcoidosis is a systemic granulomatous inflammatory disorder and can present similarly but remains low on differential in a man with no history of any respiratory conditions. The lack of the intraorbital mass biopsy is a limitation of this report. The biopsy was deferred due to the rapid reduction of the size of this mass associated with improvement in symptoms.

GCA is an inflammatory vasculopathy affecting medium and large vessels with well-developed vasa vasorum. ${ }^{4}$ Given how rare coexisting intraorbital inflammation is, any accurate estimates of their incidence along with GCA are not currently available., However, unlike the current case, orbital inflammation is also accompanied by other typical GCA clinical features including new-onset headache, scalp tenderness, jaw and tongue claudication, systemic symptoms such as fever, weight loss, malaise, and joint pain, and increased inflammatory markers. PMR is found coexistent with GCA in about $30 \%-40 \%$ of cases. ${ }^{4}$ The diagnosis heavily relies on the presence of abnormal inflammatory markers. In fact, a large cohort study showed that only $4 \%$ of biopsy-proven GCA cases have normal inflammatory markers. ${ }^{7} \mathrm{TAB}$ remains the gold standard in diagnosing this condition and characteristically shows panarteritis (figure, C.a, C.b, C.c). The presence of giant cells is not required to make the diagnosis. The fragmentation of internal elastic lamina is a highly pathognomonic feature of GCA (figure, C.d).

Rapid institution of glucocorticoids (GC) remains the mainstay of treatment of GCA, with variable duration of treatment depending on individual treatment response as GCA is associated with a high risk of relapse. ${ }^{8}$ Several steroidsparing agents like TNF- $\alpha$ inhibitors have also been studied with varying degree of success. ${ }^{9}$ More recently, tocilizumab, an interleukin- 6 a receptor blocker, has been shown to reduce relapse rates when used with GC in a phase III study. ${ }^{10} \mathrm{Al}-$ though these results are promising, more research is needed to evaluate the safety and efficacy of this agent.

This case represents an uncommon presentation of a common condition and emphasizes the importance of considering GCA in the differential diagnosis of any form of acute monocular vision loss. The atypical features of this case, including the lack of headache, myalgia, and other GCA systemic symptoms with normal inflammatory markers and the presence of bilateral orbital mass lesions made for a challenging diagnosis. The treatment of GCA is time-sensitive and delayed treatment is associated with poor visual outcomes. Despite several atypical features, a high vigilance for the possibility of this condition led to the correct diagnosis and prevented a potentially poor longterm visual outcome.

\section{Author contributions}

Dr. Bhatt: study concept and design, analysis and interpretation of data, critical revision of manuscript for intellectual content. Dr. Landman: study concept and design, analysis and interpretation of data. Dr. Sidani: analysis and interpretation of data. Dr. Asdaghi: study supervision, study concept and design, analysis and interpretation of data, critical revision of manuscript for intellectual content.

\section{Acknowledgment}

The authors thank Dr. Sander R. Dubovy, Department of Ophthalmology, Bascom Palmer Eye Institute, University of Miami, for providing the pathology slides for this case.

\section{Study funding}

No targeted funding reported.

\section{Disclosure}

The authors report no disclosures relevant to the manuscript. Go to Neurology.org/N for full disclosures. 


\section{References}

1. Mitchell JR, Krashin-Bichler I, Rosenblum M, Diamond EL, Dinkin MJ. Giant cell arteritis presenting with bilateral orbital inflammatory disease and enhancing superficial temporal arteries. Pract Neurol 2014;14:446-447.

2. Lee AG, Tang RA, Feldon SE, et al. Orbital presentations of giant cell arteritis. Graefes Arch Clin Exp Ophthalmol 2001;239:509-513.

3. Morgenstern KE, Ellis BD, Schochet SS, Linberg JV. Bilateral optic nerve sheath enhancement from giant cell arteritis. J Rheumatol 2003;30:625-627.

4. Weyand CM, Goronzy JJ. Medium- and large-vessel vasculitis. N Engl J Med 2003; 349:160-169.

5. D’Souza NM, Morgan ML, Almarzouqi SJ, Lee AG. Magnetic resonance imaging findings in giant cell arteritis. Eye 2016;30:758-762.
6. Islam N, Asaria R, Plant GT, Hykin PC. Giant cell arteritis mimicking idiopathic orbital inflammatory disease. Eur J Ophthalmol 2003;13:392-394.

7. Kermani TA, Schmidt J, Crowson CS, et al. Utility of erythrocyte sedimentation rate and C-reactive protein for the diagnosis of giant cell arteritis. Semin Arthritis Rheum 2012;41:866-871.

8. Kermani TA, Warrington KJ, Cuthbertson D, et al. Disease relapses among patients with giant cell arteritis: a prospective, longitudinal cohort study.J Rheumatol 2015;42:1213-1217.

9. Salvarani C, Macchioni P, Manzini C, et al. Infliximab plus prednisone or placebo plus prednisone for the initial treatment of polymyalgia rheumatica: a randomized trial Ann Intern Med 2007;146:631-639.

10. Stone JH, Tuckwell K, Dimonaco S, et al. Trial of tocilizumab in giant-cell arteritis. N Engl J Med 2017;377:317-328. 


\section{Neurology}

\section{Clinical Reasoning: A case of bilateral orbital mass lesions presenting with acute monocular vision loss}

Nirav Bhatt, Avi Landman, Charif Sidani, et al.

Neurology 2018;91;e2192-e2196

DOI 10.1212/WNL.0000000000006624

This information is current as of December 3, 2018

\section{Updated Information \&} Services

References

Citations

Subspecialty Collections

Permissions \& Licensing

Reprints including high resolution figures, can be found at: http://n.neurology.org/content/91/23/e2192.full

This article cites 10 articles, 3 of which you can access for free at: http://n.neurology.org/content/91/23/e2192.full\#ref-list-1

This article has been cited by 1 HighWire-hosted articles: http://n.neurology.org/content/91/23/e2192.full\#\#otherarticles

This article, along with others on similar topics, appears in the following collection(s):

Optic nerve

http://n.neurology.org/cgi/collection/optic_nerve

Orbit

http://n.neurology.org/cgi/collection/orbit

Other cerebrovascular disease/ Stroke

http://n.neurology.org/cgi/collection/other_cerebrovascular_disease_s troke

Vasculitis

http://n.neurology.org/cgi/collection/vasculitis

Visual loss

http://n.neurology.org/cgi/collection/visual_loss

Information about reproducing this article in parts (figures,tables) or in its entirety can be found online at:

http://www.neurology.org/about/about_the_journal\#permissions

Information about ordering reprints can be found online:

http://n.neurology.org/subscribers/advertise

Neurology ${ }^{\circledR}$ is the official journal of the American Academy of Neurology. Published continuously since 1951, it is now a weekly with 48 issues per year. Copyright @ 2018 American Academy of Neurology. All rights reserved. Print ISSN: 0028-3878. Online ISSN: 1526-632X.

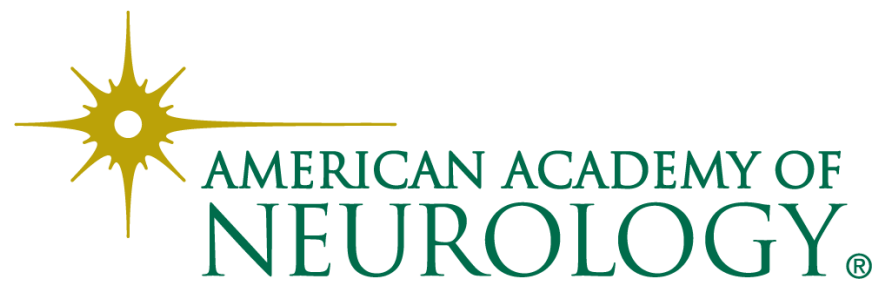

